\title{
'Phenome' project set to pin down subgroups of autism
}

Scientists are set to begin the autism 'phenome' project, which aims to classify the differences in autistic children. Identifying the molecular and anatomical variations of the disease might allow researchers to tailor treatments.

Autism is a developmental disorder marked by learning deficits and poor social skills. But autistic children also often show a host of other problems, including seizures and gastrointestinal disorders. Scientists have been unable to pinpoint the genetic or environmental causes of the disorder, in part because both appear to differ in subgroups of affected children.

The phenome project aims to classify the biomedical and behavioral aspects of the disorder. "The goal is to take autism as we know it and fractionate into more homogenous subtypes," says David Amaral, research director of the MIND Institute at the University of California in Davis.

A pilot version of the project—given high priority in the US National Institutes of Health's 2003 research roadmap—has already begun at the MIND Institute. Scientists plan to ultimately run rigorous genetic, proteomic, anatomic and immune tests on 1,800 children-600 with autism, 600 with other developmental disabilities and 600 normally

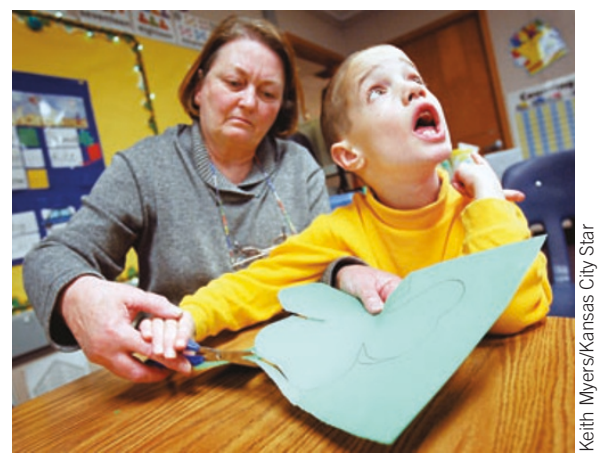

Scientists plan to classify the symptoms of autism, which can vary dramatically.

developing children — at four US sites.

Autistic children have striking variations in proteins and immune cells in their blood, Amaral reported at a conference in Boston in May. He and his colleagues analyzed 4,000 proteins in 105 children - 70 with autism and 35 without — and found significant differences in the levels of 100 proteins. They also found that autistic children had higher levels of B cells and natural killer cells. In a second study, immunologist Judy Van de Water found that immune cells collected from autistic children respond differently to bacteria and viruses than those from normally developing children.
Scientists plan to investigate these differences in the phenome project. Amaral also hopes to analyze the blood of young infants to find a predictive biomarker for autism.

The MIND Institute has raised more than $\$ 1$ million to support the first 18 months of the project. Funds for the remaining costsapproximately $\$ 30$ million-have not yet been lined up.

In the project's first phase, the researchers plan to follow 55 children for five to eight years after diagnosis. The children will be given a thorough medical checkup, including assessment of brain size, genetic studies to look for candidate genes and blood tests to find differences in protein composition.

The researchers plan to pool their data on a publicly accessible database. The project will help scientists interpret the genetics data collected by the autism community and study gene-environment interactions, says Dan Geschwind, a neuroscientist at the University of California at Los Angeles.

The researchers also plan to study which treatments work best for specific subtypes of the disorder, which could help doctors intervene earlier. "We have a window of opportunity for treatment," says Amaral. "If you get it wrong, you can't go back."

Emily Singer, Boston

\section{Spanish scientists say goodbye to popular Juan March meetings}

Much to Spanish scientists' dismay, the

Fundación Juan March, which has for decades supported international meetings and research grants for biomedical research, has decided to end its commitment to biology. Its last biology meeting, on uncoupling proteins, was held in April 2005.

Foundation officials say they have ended the program because it has achieved its goals. "A stage has already been fulfilled," says Javier Goñi, a spokesman for the foundation. Officials reportedly told the foundation's scientific council that it would now focus on other topics, such as philosophy.

Established in 1955 by Spanish entrepreneur Juan March-Ordinas, the foundation is a family-run institution that, till this year, dedicated its resources to promoting biomedical research, including neurobiology, genetics and biophysics.

The foundation is best known for its international conferences in biology. Since 1992 , it has organized monthly three-day workshops on topics determined by experts, including several Nobel Laureates. Each workshop hosted about 20 speakers and 30 attendees. By the end of 2004, the foundation had organized about 200 workshops at its headquarters in Madrid. Scientific journals, primarily those belonging to Cell Press, often published reports from the meetings.

In 1981, the institution also promoted an eight-year Plan of Molecular Biology and Its Applications aimed at training Spanish and foreign researchers through nearly 200 grants. The decision to end the grants program is "a pity and a loss," says Jorge Moscat, a researcher at Madrid's Molecular Biology Center. Moscat in 2001 received $\$ 1$ million as part of the foundation's initiative to back young Spanish researchers.

Rafael Yuste, associate professor of neurobiology at Columbia University and son of former director José Luis YusteGrijalba, says at least a part of the decision is because of budget constraints on the
March family's businesses. But Goñi says the decision to cancel was not based on financial reasons.

In a statement to Nature Medicine, the foundation said it will continue its support of biomedical research by co-sponsoring the 'Cantoblanco Workshops,' set to begin in the fall at Madrid Autonomous University. But those meetings will be held without the foundation's input in selecting topics.

"The workshops were undoubtedly the greatest scientific event seen in Spain over the last years," says Luis Enjuanes, a researcher at Madrid's National Center of Biotechnology, who in April participated in a seminar that paid homage to the foundation. "I personally think that the cancellation is a catastrophe for the Spanish scientific system."

Xavier Bosch, Barcelona

For more news and analysis go to news@nature.com www.nature.com/news 